\title{
Numerical efficiency evaluation of a vertical axis turbine equipped with 4 digits and 5 digits NACA airfoils
}

\author{
${\text { Florina } \text { Costea }^{1 *} \text {, and Ion Malael }}^{1}$ \\ ${ }^{1}$ Romanian Research and Development Institute for Gas Turbines, COMOTI, Romania
}

\begin{abstract}
In the current age of global energy crisis, a run for the use of renewable energy resources as the wind energy has gained a significant attention. The main objective of this study is the comparison between two wind turbine configurations. These two turbines have the same geometric parameters but one with a 4 digits NACA0018 blades and the other with 5 digits NACA63-415 blades. In this scientific paper, a numerical evaluation of the airfoil shape influence on the VAWT efficiency is done. For this study the CFD methods with Ansys Fluent software, are used. All the simulations are for unsteady flow at 1e06 Reynolds number value with SST turbulence model. At the design point the wind velocity is $12 \mathrm{~m} / \mathrm{s}$ and for the wind turbine geometric features, the diameter is $3.25 \mathrm{~m}$ and the height $4.87 \mathrm{~m}$. The power coefficient variation through tip speed ratio will be represented for each wind turbine configurations. To estimate the recirculation zone effects on the efficiency, the vorticity magnitude contours are presented for different positions of the blades. The results will indicate the feasibility of optimization of future wind turbine more complex airfoils.
\end{abstract}

\section{Introduction}

Nowadays, sustainable energy represents a promising source of energy in our increasing environmental issues. Wind energy is an endless resource and one of the fastest emerging renewable energy technologies. The functionality of wind turbines consists in converting the kinetic energy of wind into electricity [1]. This type of technology has a significant growth worldwide and the total world installed capacity by wind industry has increased from $1.29 \mathrm{GW}$ in 1995 to $370 \mathrm{GW}$ by the end of 2015 and many countries has the target to use $20 \%$ of their energy consumption by 2020 from renewable energy resources other countries as Denmark has decided to reach $100 \%$ of renewable energy by 2050 [2]. Vertical axis wind turbines (VAWT) and horizontal axis turbines (HAWT) are two types of wind turbine both with their own advantages and 1.disadvantages. The main advantages of vertical axis types are their capacity to catch wind coming in any direction without yawing and are able to function in more irregular wind patterns [3]. Despite HAWTs are dominant commercially because of their better aerodynamic and better efficiency, VAWTs have better feasibility for on-shore applications [4]. The VAWT inherent advantages outperform their direct horizontal-axis competitors by: independence operation of wind direction, the turbine quietness, lower complex structure maintenance cost, enhanced performance in skewed, low mechanical vibrations, generator often positioned on the ground, lower manufacturing [5] [6]. Although VAWT have high performance in comparison with HAWT, the aerodynamics involved is more complicated. Other concerns of this turbine are the torque oscillations and material fatigue [7] [8]. The common types of VAWTs are represented by Savonius, Darrieus wind turbine, where the first turbine is the simplest among all VAWT due to its drag type configuration [9].

Savonius rotor has a great ability to self-start in contrast with other lift type VAWT but has a poor efficiency considering its standard design [10].

Historically, the aerodynamic performance analysis of VAWT has been carried out with different methods: viscous model -Computational Fluid Dynamics (CFD), blade element moment theory and vortex models, load circulation model. The investigations carried out to study the performance characteristics of the rotor included: field experiments, numerical studies and the empirical methods based on data from wind tunnel tests [11] [12].

The development of computers and algorithms has led to an improved method, respectively the use of computational fluid dynamics of the H-rotor used in this scientific paper. In this method the fluid field determined around the wind turbine provides significant data for analysis. Some previous milestones involved the numerical investigation of VAWT using 2D models and focused primarily on CFD simulation of $\mathrm{H}$-rotor turbine with various specifications and parameters.

M. Kortleven et al. [13] used the computational fluid dynamics (CFD) to verify and optimize a vertical axis wind turbine. In this research were used and compared several turbulence models. The SST k-w turbulence model gave the best results with an increase in accuracy

\footnotetext{
* Corresponding author: florina.costea@,comoti.ro
} 
of the simulations in comparison with transition SST model.

Biadgo et al. [14] verified numerically a straight blade pitch VAWT using NACA 0018 airfoil. He has done the simulation for two - dimensional unsteady flow using Ansys Fluent. The results showed performance at lower speed ratios.

Suffer et al. [15] studied the aerodynamic performance of a cavity type vertical axis wind turbine. The numerical analysis was performed using the Shear Stress Transport (SST) k-w turbulence model. The numerical results demonstrated good agreement with the experimental results.

Castelli et al. [16] performed a calculation of rotor performance of two airfoil sections using CFD analysis. A numerical quantification was achieved of the influence of both configurations on overall performance.

In this scientific paper 2D flow simulations of VAWT with different airfoils was done by using the CFD methods.

\section{Wind turbine design}

The goal of this research is to find the highly efficient VAWT models by comparing two NACA airfoil configurations. Those airfoils are presented in figure 1 .

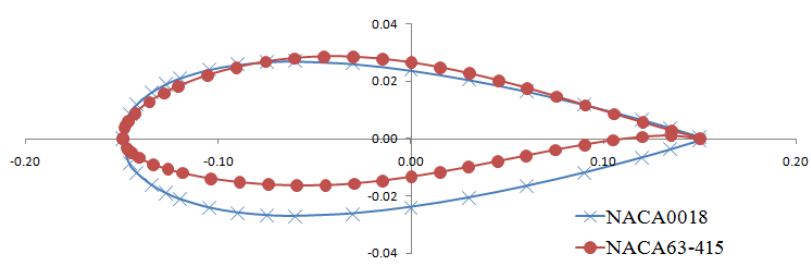

Fig. 1. Airfoils NACA 0018 and NACA 63-415.

Using the equation (1) the reference surface and the wind turbine diameter for a $5 \mathrm{~kW}$ power VAWT was determined. In the table 1 shows the geometric features of the wind turbines.

$$
\mathrm{P}_{\text {wind }}=\frac{1}{2} \rho S \mathrm{SV}_{\infty}^{3} \mathrm{C}_{\mathrm{p}}
$$

where: $\mathrm{P}_{\text {wind }}$ is the wind power, $\rho$ is the air density, $\mathrm{S}$ is the reference surface, $V_{\infty}$ is the wind velocity and $C_{p}$ is the power coefficient.

$$
\begin{aligned}
& \mathrm{C}_{\mathrm{pT}}=\frac{\mathrm{P}_{\mathrm{T}}}{\mathrm{P}_{\mathrm{wind}}}=\frac{\mathrm{M} \cdot \omega}{\frac{1}{2} \rho \mathrm{SV}_{\infty}^{3}}=\frac{\frac{1}{2} \rho S \mathrm{SV}_{\infty}^{2} \mathrm{LC}_{\mathrm{m}} \omega}{\frac{1}{2} \rho \mathrm{SV}_{\infty}^{3}}= \\
& =\mathrm{C}_{\mathrm{m}} \cdot \frac{\mathrm{L} \omega}{\mathrm{V}_{\infty}}=\mathrm{C}_{\mathrm{m}} \cdot \lambda<0.593 \cong \frac{16}{27}
\end{aligned}
$$

In order to determine the optimal chord of a turbine blade was expressed solidity relative to the turbine rotor radius.

$$
\sigma=\frac{N c}{R}
$$

\begin{tabular}{|c|c|c|c|}
\hline Parameters & \multicolumn{2}{|c|}{ Value } & Units \\
\hline Power & \multicolumn{2}{|c|}{5000} & {$[\mathrm{~W}]$} \\
\hline Turbine diameter & \multicolumn{2}{|c|}{3.25} & {$[\mathrm{~m}]$} \\
\hline Turbine height & \multicolumn{2}{|c|}{4.875} & {$[\mathrm{~m}]$} \\
\hline Blade no. & \multicolumn{2}{|c|}{3} & - \\
\hline Wind velocity & \multicolumn{2}{|c|}{12} & {$[\mathrm{~m} / \mathrm{s}]$} \\
\hline Blade chord & \multicolumn{2}{|c|}{0.3} & {$[\mathrm{~m}]$} \\
\hline Airfoils & $\begin{array}{c}\text { NACA } \\
0018\end{array}$ & $\begin{array}{l}\text { NACA } \\
63-415\end{array}$ & - \\
\hline
\end{tabular}

Table 1. Geometry of the VAWTs.

\section{CFD setup}

For this study a dedicated analysis of two-dimensional (2D) simulation is provided. This kind of simulations provides an accurate estimation of the turbine performance and a reasonable computational cost [17].

The 3-straight bladed VAWT operates several tip speed ratios using two dimensional simulations with unsteady Reynolds-averaged Navier Stokes. For a converged solution it was used a minimum number of turbine revolutions of 6 revolutions.

The two-dimensional computational domain where designed by using ANSYS ICEM. This domain is split in two subdomains. The rotor subdomain has a radius of $\mathrm{R}=1.925 \mathrm{~m}$ and the stator domain is 7 times bigger. The figure 2 it's shown the computational domain with the boundary conditions used in the CFD simulations.

The boundary conditions for the stator and rotor part where set as fluid and for the blades and the shaft where set as walls. The inlet of the computational flow domain was defined as a velocity inlet boundary with a constant velocity of $12 \mathrm{~m} / \mathrm{s}$. The wind velocity is located around the entire circumference of the turbine because the inlet of the numerical domain is dimensionally constrained only within the positive $\mathrm{X}$ axis.

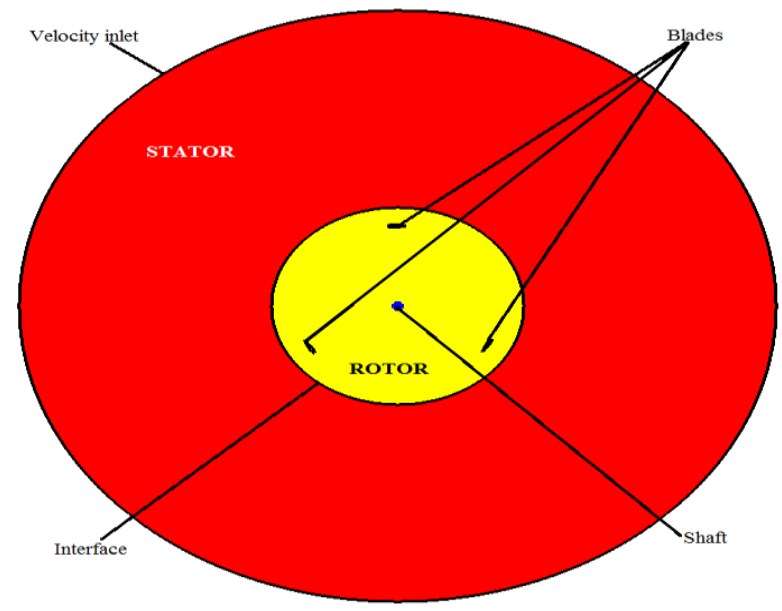

Fig.2. Computational domain and BC.

The structured mesh was generated in ICEM CFD for each case. The initial parameters listed in the Table 1 were incorporated into mesh generation software. The base of the mesh generation settings is the wall first element where $\mathrm{ds}=7 \times 10^{-6} \mathrm{~m}$ considering a reference length of $0.3 \mathrm{~m}$, Reynolds number of $1 \mathrm{e} 06$ and $\mathrm{y}^{+}=1$. For the grid spacing ratio it was used a value of 1.2. The 
mesh for each case has over 500k quad elements. In figure 3 is represented the discretization domain with close-up for each configuration.

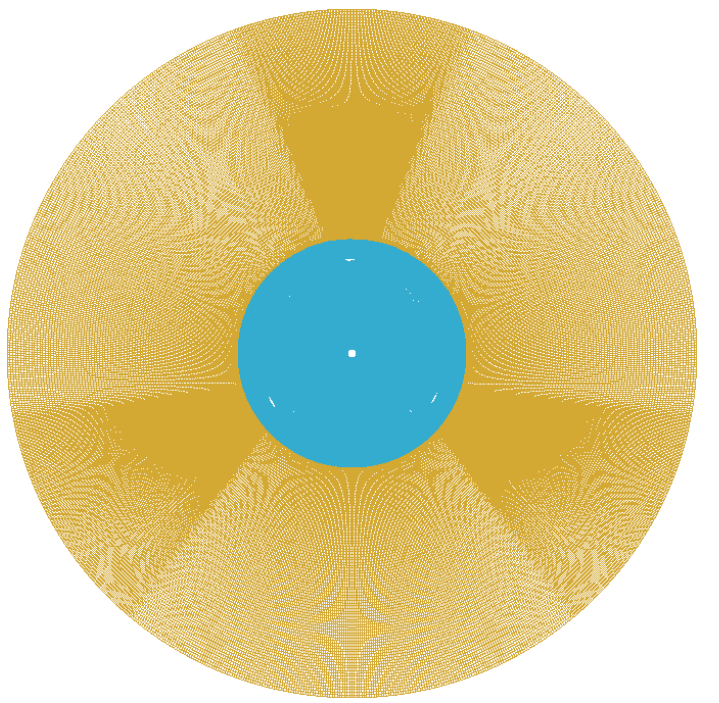

a)

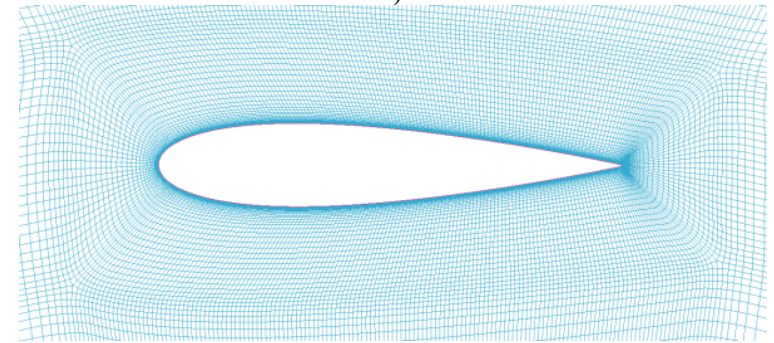

b)

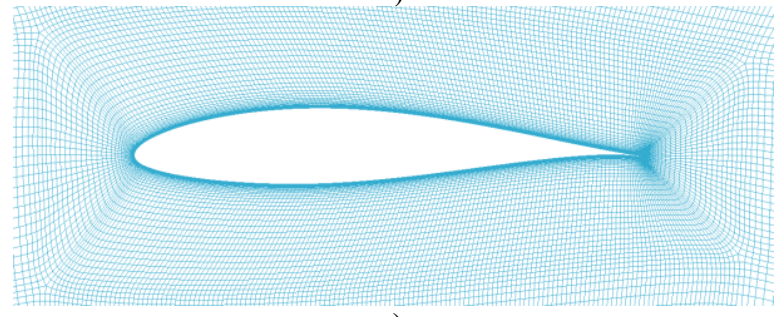

c)

Fig.3. Mesh: a) for all subdomains; b) close-up NACA0018; c) close-up NACA63-415.

The inherent unsteady aerodynamic behavior due to the fact that VAWT has a rotational axis perpendicular to the oncoming airflow, can be addressed by CFD simulations software. This unsteady aerodynamic behavior it is caused by the variation of angle of attack with the angle of rotation, the apparent velocity and the Reynolds number. By using numerical analysis and considering both wind turbine airfoils, the influence of mesh quality, airfoil shape, turbulence model and Reynolds number, we can correctly predict the efficiency. Unsteady Reynolds averaged Navier-Stokes (URANS) is used within the geometry characteristics of both configurations to determine the influence of the airfoils in the wind turbine performance.

The SST turbulence model has been chosen to perform the transient simulations. The turbine will operate at a fixed wind of $12 \mathrm{~m} / \mathrm{s}$ and at several TSR (tip speed ratio) values. The SST k-w turbulence model was introduced by Menter in 1993 is a two- equation eddyviscosity model [18].

The transport equation for turbulent kinetic energy k:

$$
\begin{aligned}
& \frac{\partial k}{\partial t}+\bar{u} \frac{\partial k}{\partial x}+\bar{v} \frac{\partial k}{\partial y}+\bar{w} \frac{\partial k}{\partial z}= \\
& =\frac{1}{\rho}\left[\frac{\partial}{\partial x}\left(\Gamma_{k} \frac{\partial k}{\partial x}\right)+\frac{\partial}{\partial y}\left(\Gamma_{k} \frac{\partial k}{\partial y}\right)+\frac{\partial}{\partial z}\left(\Gamma_{k} \frac{\partial k}{\partial z}\right)\right]+ \\
& +\widetilde{G}_{k}-Y_{k} .
\end{aligned}
$$

The transport equation for specific dissipation $\omega$ :

$$
\begin{aligned}
& \frac{\partial \omega}{\partial t}+\bar{u} \frac{\partial \omega}{\partial x}+\bar{v} \frac{\partial \omega}{\partial y}+\bar{w} \frac{\partial \omega}{\partial z}= \\
& =\frac{1}{\rho}\left[\frac{\partial}{\partial x}\left(\Gamma_{\omega} \frac{\partial \omega}{\partial x}\right)+\frac{\partial}{\partial y}\left(\Gamma_{\omega} \frac{\partial \omega}{\partial y}\right)+\frac{\partial}{\partial z}\left(\Gamma_{\omega} \frac{\partial \omega}{\partial z}\right)\right]+ \\
& +G_{\omega}-Y_{\omega}+D_{\omega} .
\end{aligned}
$$

where: $\Gamma_{\mathrm{k}}$ and $\Gamma_{\omega}$ are the effective diffusivities for $\mathrm{k}$ and $\omega ; D_{\omega}^{+}$- the positive portion of the cross diffusion term; $\widetilde{G}_{k}$ - the production of turbulence kinetic energy; $G_{\omega}$ - the production of $\omega$.

The inlet is defined as a velocity inlet. For both configurations we set the turbulent intensity at $1 \%$ and a turbulent viscosity ratio at 1 .

In the transient simulations, the blades were set to rotate in one degree increment per time step.. The inlet velocity was imposed at $12 \mathrm{~m} / \mathrm{s}$ and the rotation period for the rotor domain was calculated for all six corresponding tip speed ratios.

\section{Results and discussions}

Two representations of the vorticity magnitude $(0-250 \mathrm{~s}-$ 1 and $0-750 \mathrm{~s}-1)$ and four different angles are presented. The estimation of the circulation regions is translated into losses. TSR 1 represents the turbine acceleration and the TSR 3 nominal operating point. Vorticity is used to prove the flow influence of one blade to another. The moment coefficient variation around the wind turbine for both NACA airfoils was plotted in Fig. 8 and Fig. 9. It is observed that moment coefficient increases at the first four TSR's for both NACA profiles (from TSR 1 to TSR 2.5) and decreases after TSR 2.5 for both NACA configurations. The moment coefficient values are presented in table 2 and 3.

The maximum $\mathrm{Cm}$ of 0.48 (at TSR 3) and $\mathrm{Cp}$ of 0.61 , for the NACA 63-415airfoil, was found as the optimum airfoil parameters in order to achieve maximum performance for a three straight-bladed VAWT.

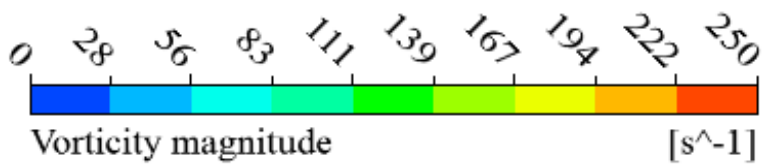




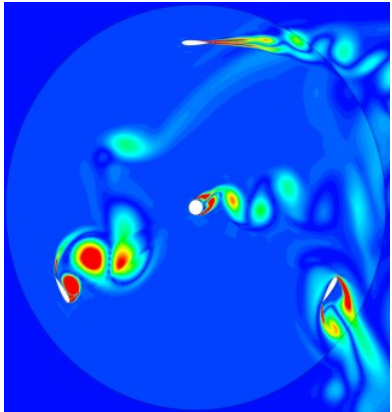

a)

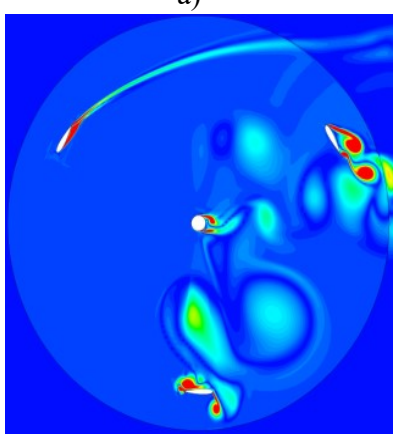

c)

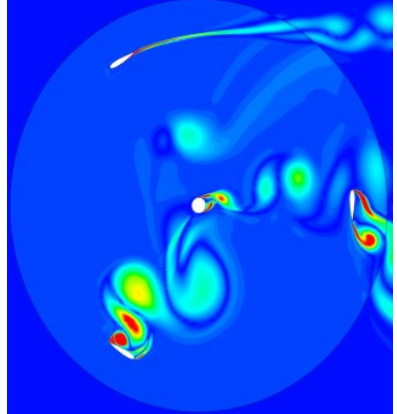

b)

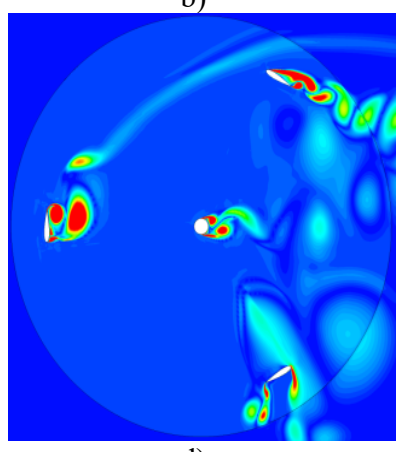

d)

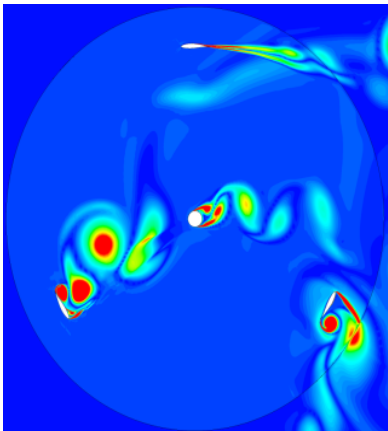

a)

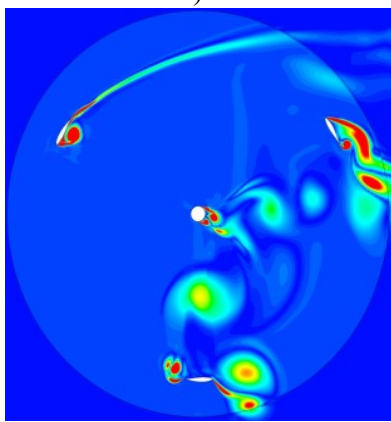

c)

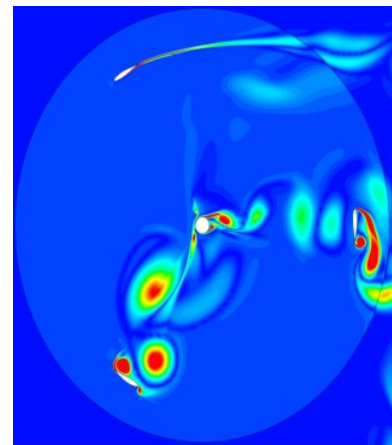

b)

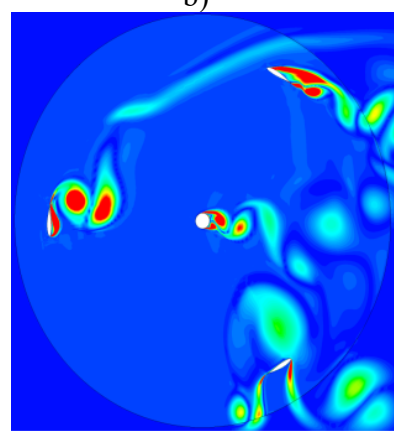

d)

Fig. 4. Vorticity magnitude of NACA 0018 for $T S R=1$ at a) $0^{\circ}$ b) $30^{\circ}$ c) $60^{\circ}$ d) $90^{\circ}$.

Fig. 6. Vorticity magnitude of NACA 63-415 for $\mathbf{T S R}=1$ at a) $0^{\circ}$ b) $30^{\circ}$ c) $60^{\circ}$ d) $90^{\circ}$.

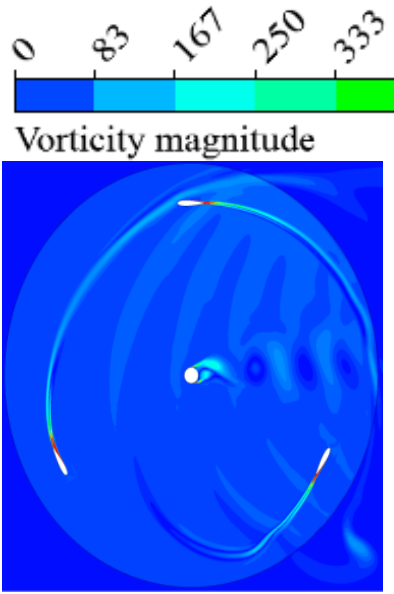

a)

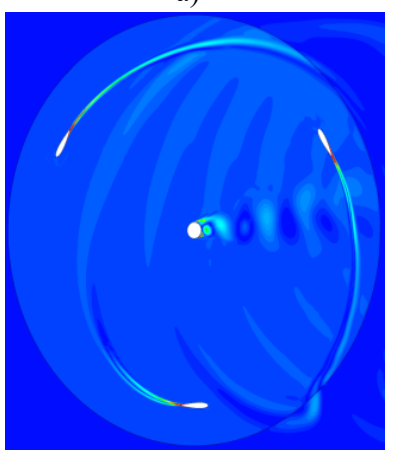

c)
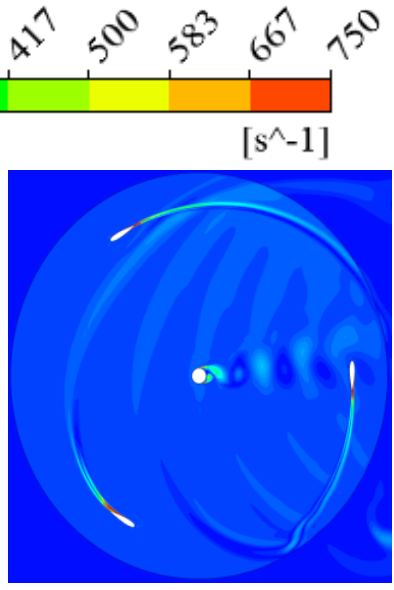

b)

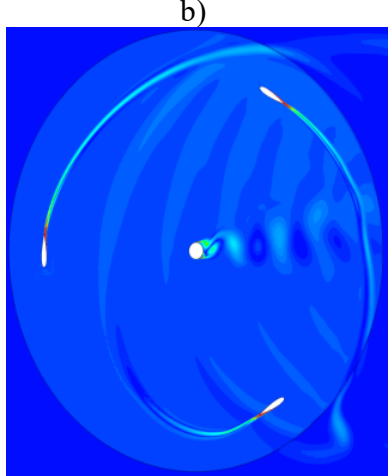

d)

Fig. 5. Vorticity magnitude of NACA 0018 for $T S R=3$ at a) $0^{\circ}$ b) $30^{\circ}$ c) $60^{\circ}$ d) $90^{\circ}$.

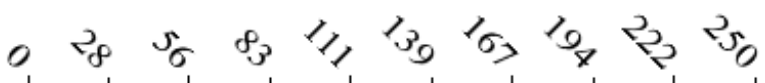

Vorticity magnitude

$\left[\mathrm{s}^{\wedge}-1\right]$

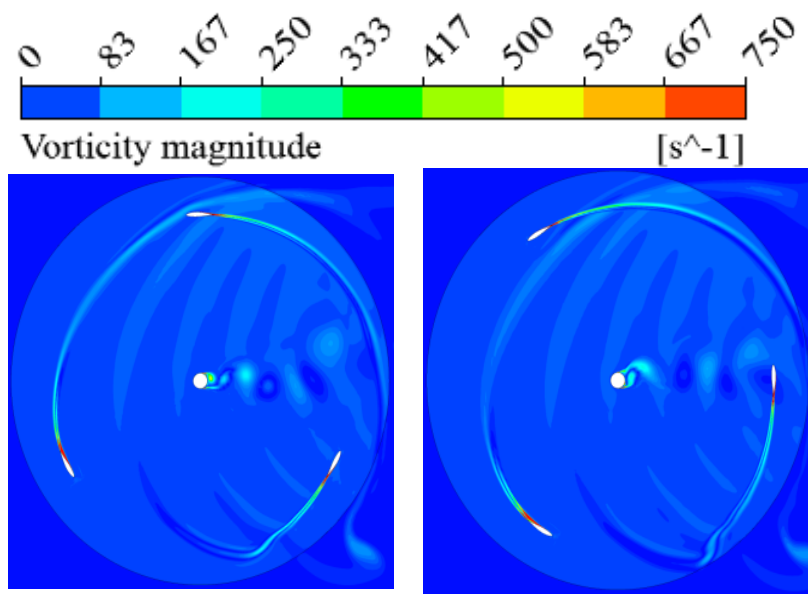

a)

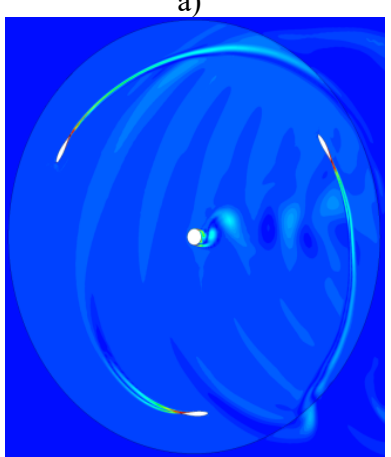

c)

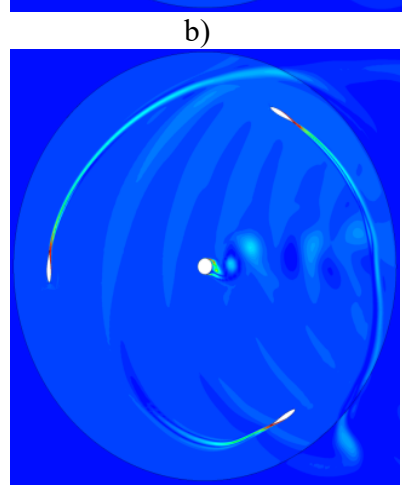

d)

Fig. 7. Vorticity magnitude of NACA 63-415 for $T S R=3$ at a) $0^{\circ}$ b) $30^{\circ}$ c) $60^{\circ}$ d) $90^{\circ}$.

The moment coefficient $\left(\mathrm{C}_{\mathrm{m}}\right)$ variations around the wind turbine for NACA 0018 and NACA 63-415 at various TSR are represented in the following figures: 


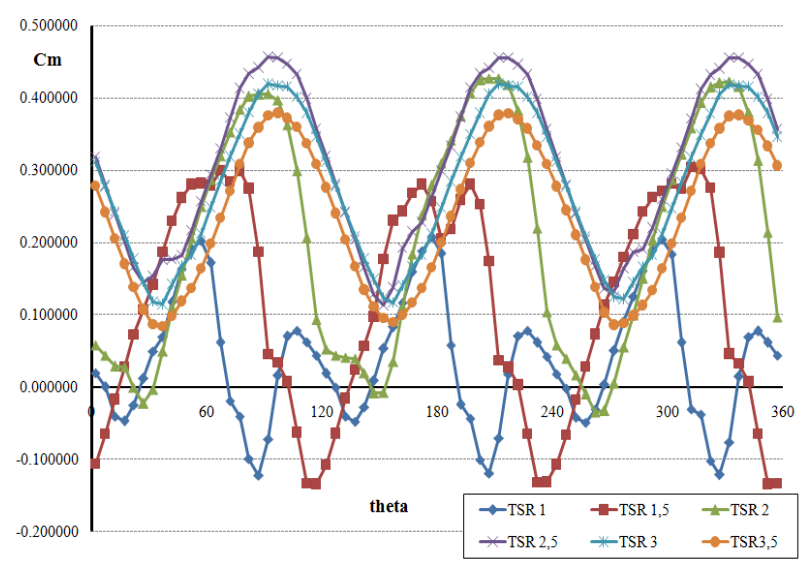

Fig. 8. Moment coefficient variations for NACA 0018.

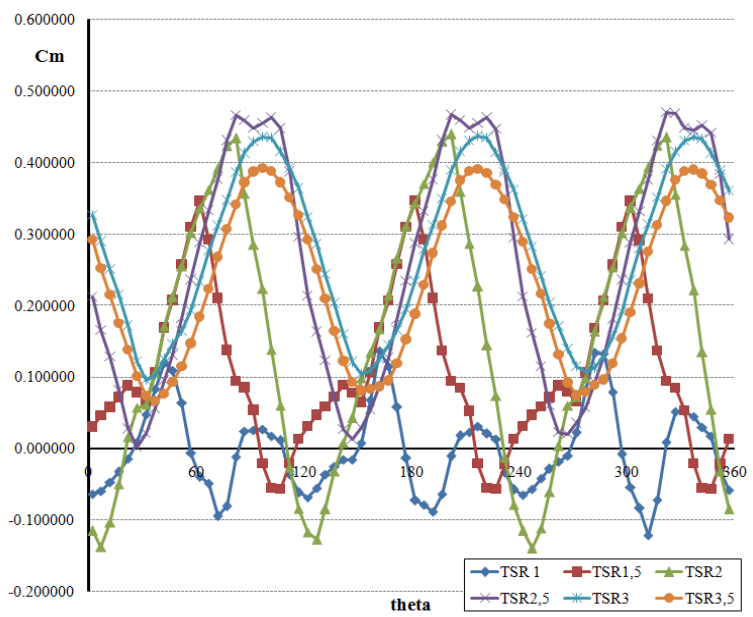

Fig. 9. Moment coefficient variations for NACA 63415.

Table 2. Minimum and maximum $\mathrm{Cm}$ values at different TSR for NACA 0018 .

\begin{tabular}{|c|c|c|}
\hline TSR & Max. Cm & Min. Cm \\
\hline 1 & 0.20 & -0.12 \\
\hline 1.5 & 0.30 & -0.14 \\
\hline 2 & 0.43 & -0.04 \\
\hline 2.5 & 0.46 & 0.15 \\
\hline 3 & 0.41 & 0.11 \\
\hline 3.5 & 0.39 & 0.08 \\
\hline
\end{tabular}

Table 3. Minimum and maximum $\mathrm{Cm}$ values at different TSR for NACA 63-415.

\begin{tabular}{|c|c|c|}
\hline TSR & Max. Cm & Min. Cm \\
\hline 1 & 0.14 & -0.12 \\
\hline 1.5 & 0.35 & -0.06 \\
\hline 2 & 0.44 & -0.15 \\
\hline 2.5 & 0.48 & 0 \\
\hline 3 & 0.44 & 0.10 \\
\hline 3.5 & 0.399 & 0.07 \\
\hline
\end{tabular}

Figure 10 shows the influence of two NACA airfoils configurations for the power coefficient under TSRs. $C_{P}$ is positive at TSR $\geq 1$, which means the turbine is able to produce power without any extra power to enter continuous rotation. The shear stress transport $\mathrm{k}-\mathrm{w}$ turbulence model was used to simulate a $2 \mathrm{D}$ unsteady model of the VAWT. The simulation is 2D, which means that the blade end losses are not taken into account. That's why the power coefficient exceeds the Betz limit (eq.2). In a fully 3D CFD simulation the efficiency of a wind turbine will never pass over the Betz limit because of in that case the influence of the losses on the blade tip and the flow among the blade can be quantified.

The computational results illustrate an identical convergence at 1.5, 3 and 3.5 TSR values. The optimal point for each wind turbine configurations is for TSR equal with 3 . The results show that until TSR 3 , the performance coefficient for both configurations is proportional with the increasing tip speed ratio. The NACA 0018 gives the best overall performance. Although the NACA 63-415 gives a lower performance at the first rotational speeds or TSR, its performance at higher rotational speeds ( $\geq$ TSR3) is better, being the same with NACA 0018. Largest variation in $\mathrm{Cp}$ within the TSR range between 2-2.5 is observed at NACA 0018 which approximately constant at higher rpm.

The peak performance coefficient $\left(\mathrm{C}_{\mathrm{Pmax}}\right)$ at our Reynolds number is observed at both NACAs at TSR $=3$.

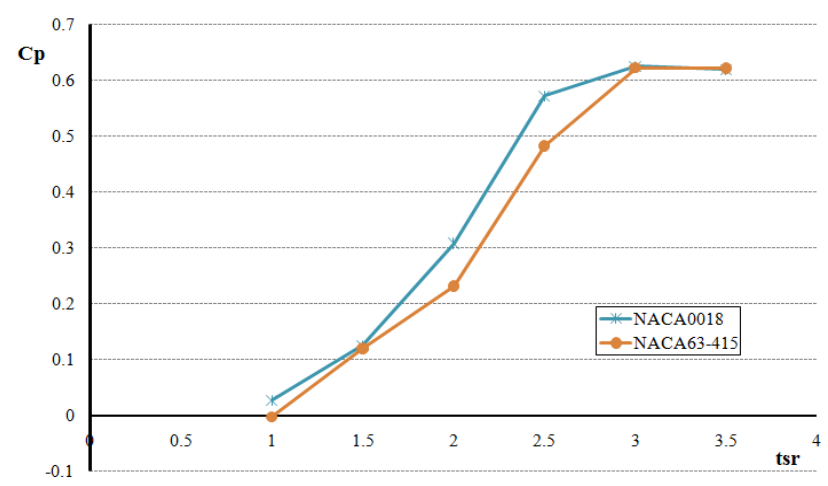

Fig. 10. Comparison of power coefficient for NACA 0018 and NACA $63-41$.

\section{Conclusions}

In this scientific paper the flow around two wind turbine configurations has been numerically analyzed, with the use of CFD methods. For these simulations, the geometry of a vertical axis wind turbine, that can generate power up to $5 \mathrm{~kW}$ of power at a wind velocity of $12 \mathrm{~m} / \mathrm{s}$, has been used. The VAWT configurations design is based on NACA 0018 and NACA 63-415 airfoils. For each case the moment coefficient were chosen, for different TSR values $(1 ; 1.5 ; 2 ; 2.5 ; 3,3.5)$. Also the wind turbine map was done by using the power coefficient variation through different values of tip speed ratio.

In the end the vorticity magnitude counters for $0^{\circ}$, $30^{\circ}, 60^{\circ}$ and $90^{\circ}$ were plotted in each configuration. In this way the recirculation zone with the flow separation can be observed and estimate the influence of flow behavior in the vertical axis wind turbine efficiency.

This work was carried out within the help of Romanian National Research and Development Institute for Gas Turbine, COMOTI. 


\section{References}

1 P.J. Schubel, R.J. Crossley, "Wind Turbine Blade Design", University of Nottingham, September 2012

2 E.J.N. Menezes, A.M. Araújo,"A review on wind turbine control and its associated methods", October 2017

3 M.R. Hasan, Md. R. Islam, G.M.H. Shahariar, M. Mashud,'Numerical Analysis of Vertical Axis Wind Turbine", Khulna University of Engineering \&Technology,2014

4 D. Ragni, C.S. Ferreira, "Experimental and numerical investigation of an optimized airfoil for vertical axis wind turbines", 32 ${ }^{\text {nd }}$ ASME Wind Energy Symposium, January 2014

5 F. Balduzzi, J. Drofelnik, A. Bianchini, G. Ferrara, "Darrieus wind turbine blade unsteady aerodynamics: a three dimensional Navier Stokes CFD assessment", Journal of Engineering for Gas Turbines and Power, August 2017

6 G.E. Hassan, A. Hassan, M. E. Youssef," Numerical Investigation of Medium Range Re Number Aerodynamics Characteristics for NACA0018 Airfoil", January 2015

7 A.M. Biadgo, A. Simonovic, Dragan Komarov, Slobodan Stupar," Numerical Analytical Investigation of Vertical Axis Wind Turbine, 2015

8 A. Goude, "Fluid Mechanics of Vertical Axis Turbine", Uppsala University, 2012

9 M. Rahman, M. Ahmed, M. Bashar, A. Mitra, T. Salyers, "Numerical and Experimental Investigations on Vertical Axis Wind Turbines of Different Models", January 2017

10 E.A.D. Kumara, N.K. Hettiarachchi, K.G.R.M. Jayathilake,"Overview of the Vertical Axis Wind Turbines", International Conference on Renewable Energies and Power Quality, Spain, March 2015

11 M.H.Mohamed, G.Janiga, E.P.D.Thévenin, "Optimal blade shape of a modified Savonius turbine using an obstacle shielding the returning blade", Energy Conversion and Management, January 2011

12 A.M. Biadgo, A. Simonovic, "Numerical and Analytical Investigation of Vertical Axis Wind Turbine", November 2015

13 S. Mohammad, E. Saryazdia and M. Boroushakib, "2D Numerical Simulation and Sensitive Analysis of H-Darrieus Wind Turbine", February 2018

14 M. Kortleven," Simulation Verification and Optimization of a Vertical Axis Wind Turbine using CFD” July 2016

15 K. Suffer, R. Usubamatov, G. Quadir, K. Ismail," Modelling and Numerical Simulation of a Vertical Axis Wind Turbine Having Cavity Vanes", Fifth International Conference on Intelligent Systems, Modelling and Simulation, 2014
16 M.R. Castelli and E. Benini, "Comparison of Two Airfoil Sections for Application in Straight-Bladed Darrieus VAWT", December 2011

17 A. Bianchini, F. Balduzzi, P. Bachant, G. Ferrara, L. Ferrari, "Effectiveness of two-dimensional CFD simulations for Darrieus VAWTs: a combined numerical and experimental assessment", 2017

18 F.R. Menter, "Two- Equation Eddy-Viscosity Turbulence Models for Engineering Applications," AIAA Journal, Vol. 32, No. 8, August 1994 